\title{
ESTIMATION OF IONOSPHERIC ENERGY DISSIPATION FOR THE YEAR 2012 USING ØSTGAARD'S EMPIRICAL RELATION
}

\author{
Sa'id, ${ }^{1}$ R. S. and Aliyu ${ }^{2}$ A. M. \\ ${ }^{1}$ Department of Physics, Faculty of Science, Bayero University, Kano, Nigeria \\ ${ }^{2}$ Department of Physics, Faculty of Science, Gombe State University, Gombe, Nigeria \\ Corresponding Author: ${ }^{1}$ rssaidu.phy@buk.edu.ng
}

\begin{abstract}
The energy dissipation in the ionosphere resulting from the geomagnetic activity have caused an increasing number of major disruptions of important power and communication services, malfunctions and loss of expensive equipment. In this paper, data for the electron precipitation energy(ep) and joule heating energy(jh) have been used in the computation of both mean daily and hourly ionospheric energy dissipation using Østgaard's empirical relation. The computation has been done for the year 2012. Hourly provisional values of geomagnetic indices obtained at International Service for Geomagnetic Indices from World Data Centre for Geomagnetism, Kyoto, Japan were used in the computation. International Association for Geomagnetism and Aeronomy (IAGA)-2002 format was adopted in the analysis. Under the assumption that the magnetosphere does not store any energy, the beginning of the event is taken as $t_{1}=0$ and ending at $t_{2}=24$ hours. This is the duration used for the estimation. The estimated amount of energy dissipated through the ionosphere within this interval was found to be1.414393E+07 $\pm 824,154.1 \mathrm{GJ}$ with $90 \%$ confidence level, which indicates that ionospheric energy dissipation is the dominant channel of energy transfer in that year from the solar wind. This is consistent with many results found by other researchers.

Keywords: Østgaard's Empirical Relation, Ionospheric Energy Dissipation, Electron Precipitation, Joule Heating
\end{abstract}

\section{INTRODUCTION}

In the Earth's magnetosphere, the solar wind energy is dissipated into various sinks during magnetic storms and substorms. The main energy dissipation channels are Joule heating, Auroral precipitation in the ionosphere, ring current encircling the earth at the equatorial plane, plasma sheet heating in the night side magnetosphere and the release of plasmoids from the magnetospheric tail. Plasma erupted from the Sun, carrying the interplanetary magnetic field, can penetrate the magnetic shielding of the Earth through a reconnection process. This merging of field lines and penetration of particles represent an energy transfer into the magnetosphere. The energy can then either be deposited "directly" into the ionosphere with a typical delay of 20 minutes or be stored in the magnetosphere and with a typical delay time of 60 minutes and then dissipated during Substorms (Liou et al., 1998).

The primary dissipation mechanisms in the ionosphere are Joule heating and particle precipitation. A number of empirical relations are used to estimate the energy dissipated via these mechanisms (Østgaard et al., 2002). The most commonly used of these formulae give the energy dissipated as a function of an Auroral index (typically $\mathrm{AE}$ or $\mathrm{AL}$ )

In this work we consider both the two ionospheric energy sinks (Joule Heating and particle precipitation) and used geomagnetic indices irrespective of the event. The data obtained at International Service for Geomagnetic Indices (ISGI) from World Data Center (WDC) Kyoto, were used as input in the relation developed by Østgaard et al, (2002) to estimate theionspheric energy dissipation.

\section{lonospheric Dissipation}

Here, we consider only two important modes of energy dissipation from the magnetosphere to ionosphere which are joule heating $w(j h)$ and electron precipitation $w(e p)$ while all other energy sinks, upward ion acceleration and kilometric radiation are much weaker, therefore total ionospheric energy dissipation is estimated as;

$$
W_{t}=w(h)+w(e p)
$$

Where $w_{t}$ is the ionospheric dissipation energy $w(j h)$ is joule heating energy and $w(e p)$ represents the energy via electron precipitation The different ionospheric dissipation channels are not totally independent of each other; for example, the electron precipitation affects 
ionospheric deposition energy indirectly through joule heating by increasing the ionospheric Pederson conductance (Østgaard et $a l, .2002)$. However, these two channels are different processes and thus cannot be estimated using the same parameter (Eija, 2002)

\section{Joule Heating Energy}

This is the energy which simply arises as a result of stream of highly charged particles (electrons) emitting from the sun current into the ionosphere which is responsible for geomagnetic disturbances. To estimate the joule heating rate there are many empirical relations using different geomagnetic indices as input to the results, but in the form of regression equation ( Østgaard et al,. 2002) :

$$
P(h)(G W)=a A E+b \quad 2
$$

Where $P(j h)$ is the joule heating rate, $A E$ corresponds to the difference between the west -ward $(A U)$ and east-ward ( $A L$ ) auroral electrojets while $a$ and $b$ are scaling factors Depending on the values of $a$ and $b$, we consider the following: we choose $A E$ index, whose values are derived from the same stations. We note also that using more stations provides greater accuracy; as an example, the $\mathrm{AE}$ indices from 68 stations is on average $35 \%$ higher in accuracy than that of $\mathrm{AE}$ from 12 stations(Lu et al., 1998), which implies that the scaling factor $a$ obtained when a large number of stations are used should be smaller when $\leqq 10$. We need a rough seasonal dependence of $a$ and $b$, which is estimated by the work of Østgaard,et al., (2002)based on a linear fit to an estimate of the height-integrated energy dissipation and high correlation coefficient given by:

$P(j h)(G W)=0.54 A E+1.8$

3

Where $P(j h)(G W)$ is the total hemispherical Joule heating rate in both the two hemispheres. Integrating equation (3) from the beginning of the event $t_{1}$ to its end $t_{2}$ with time, will give the corresponding energy in Giga joules (GJ)( Østgaard et al,. 2002).

$w(j h)=\int_{t 1}^{t 2} P(j h)(W) d t$

\section{Electron Precipitation}

Electron precipitation energy occurs when electrons energized by solar winds, which are normally trapped in the magnetosphere, are pulled into the ionosphere by waves. To obtain the power via electron precipitation in GW we used Østgaard empirical relation obtained from UV and X-ray emissions converting westward electrojet into the northern hemispherical power which is then doubled to obtain global value ( Østgaard et al.,2002).

$$
P(e p)(G W)=2\left[4.4(A L)^{1 / 2}-7.6\right] \quad 5
$$

This is then integrated to obtain the total energy via electron precipitation $w(e p)$, from beginning $t_{1}$ to the end of the event $t_{2}$ in GJ ( Østgaard et al,. 2002) .

$$
w(\mathrm{ep})=\int_{t 1}^{t 2} P(e p)(G W) d t \quad 6
$$

\section{MATERIALS AND METHODS}

The $A E, A L$ in equations (7)and (8) were used to obtain joule heating rate and power via electron precipitation. The hourly provisional Auroral Electrojet indices (AE) for 2012 were converted to mean hourly-daily geomagnetic index as follows to reduce the clusters of data. To minimize error in dealing with a cluster of $1 \mathrm{~h}$-cadre of data we centralized them to a source $K$, such that : If $x_{0}, x_{1}, x_{2}, x_{3} \ldots x_{23}$, are the hourly geomagnetic indices for a day, then

$$
K=\frac{\sum_{i=0}^{23} X_{i}}{n}
$$

If $X$ 's Geomagnetic indices are grouped into $N$ intervals, with midpoints $m_{1}, m_{2} \ldots m_{N}$ and frequencies $f_{1}, f_{2} \ldots f_{N}$, respectively, the simple arithmetic average is given by

$$
K=\frac{\sum_{i=0}^{23} f_{i} m_{i}}{\sum_{i=0}^{23} f_{i}}
$$

The mean geomagnetic index obtained from either equation (9) or (10) was used as an input to equations 2 and 6 , which we integrated to obtain an estimated energy value. 


\section{RESULTS}
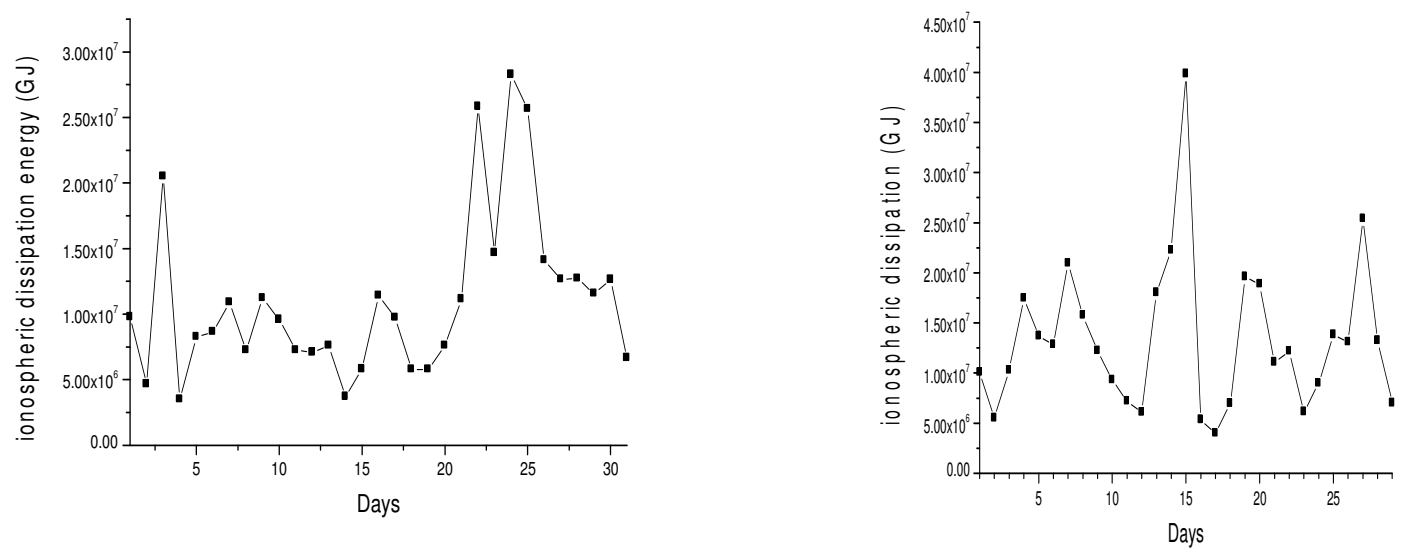

Figure1 \& 2: Mean Daily lonospheric Dissipation Energy (January \& February, 2012)
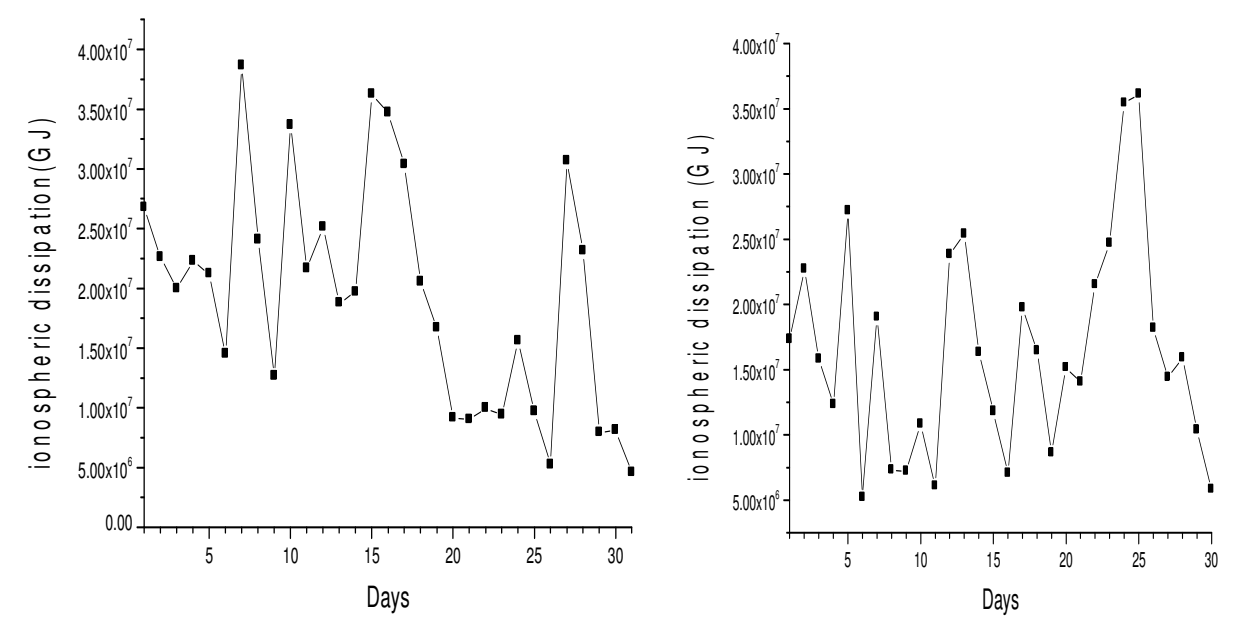

Figures 3\&4: Mean Daily lonospheric Dissipation Energy (March \& April, 2012
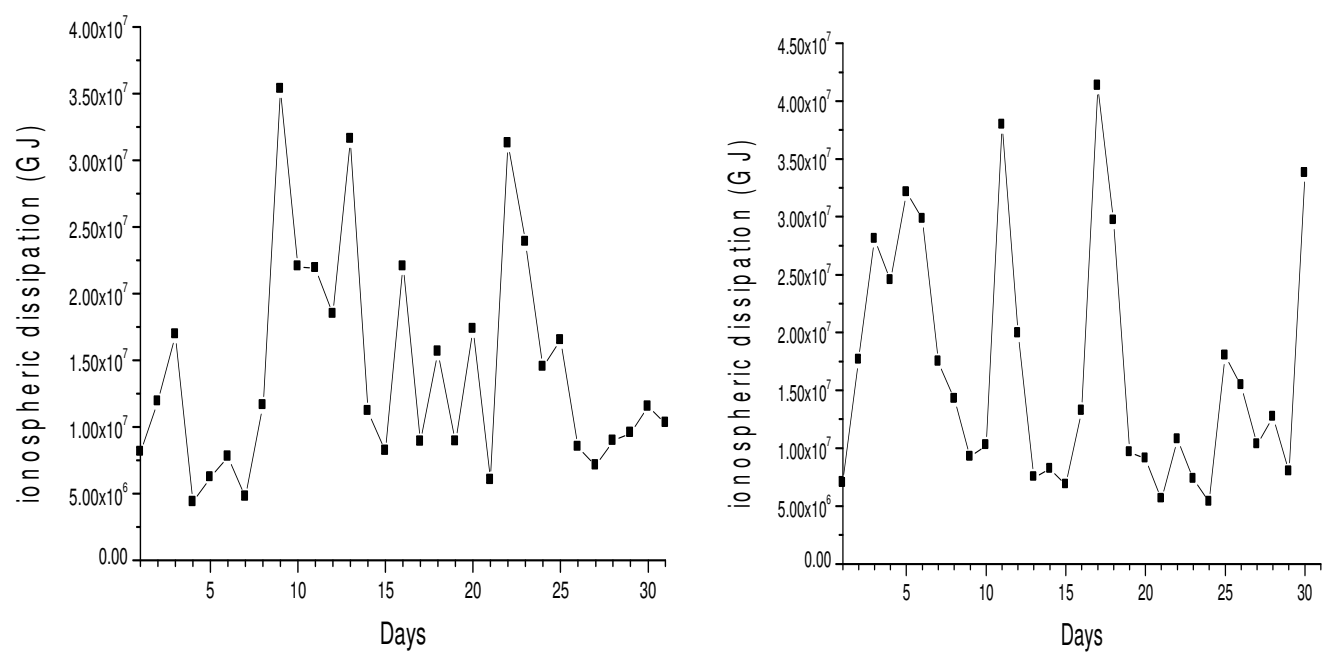

Figures 5 and 6: Mean Daily lonospheric Dissipation Energy (May\&June, 2012 


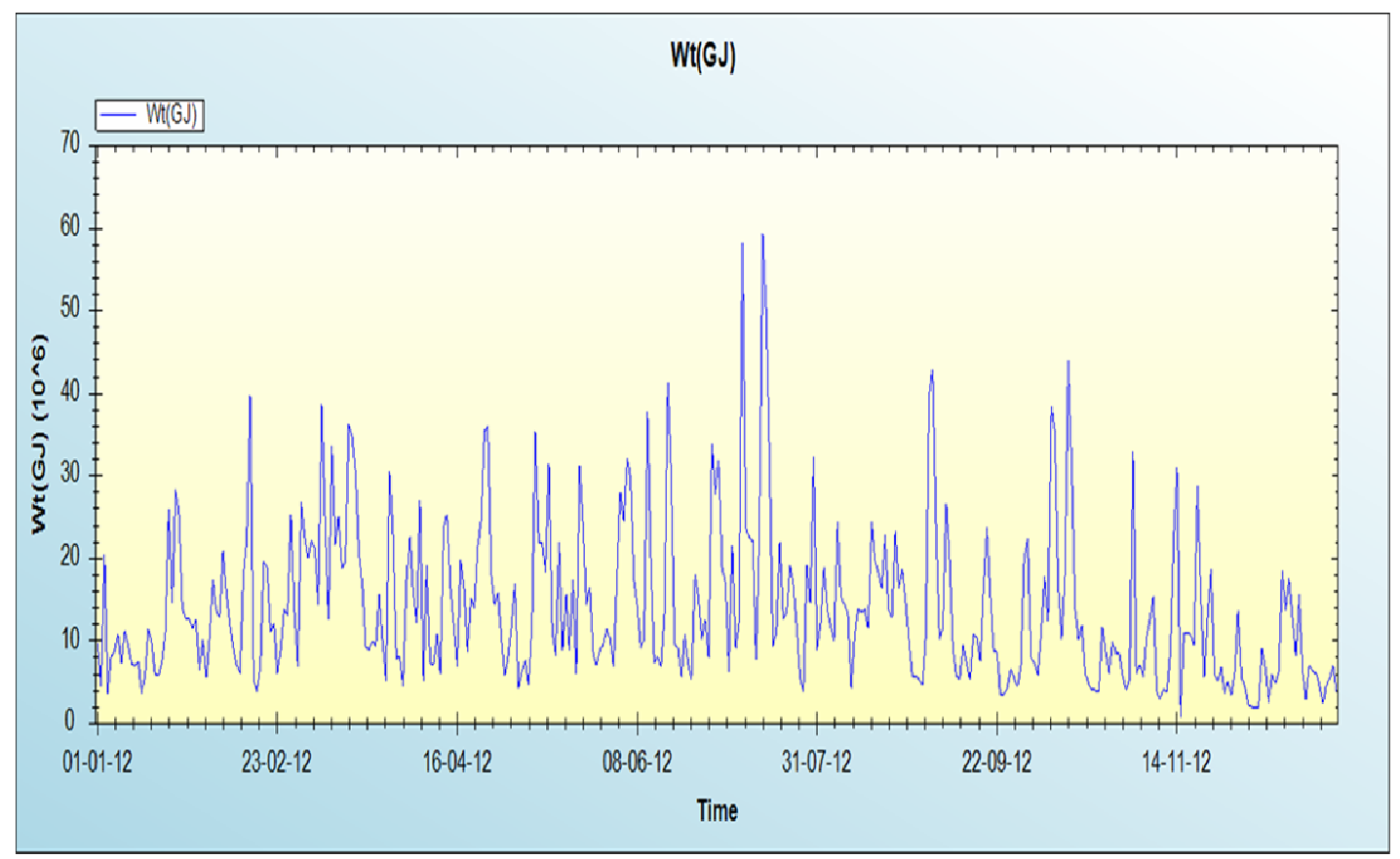

Figure7: Daily plot for Ionospheric dissipation 2012

\section{DISCUSSION}

In Figure1, during the first day of the year the dissipation energy was found to be moderate compared to other remaining days, high on $22^{\text {nd }}$ but is maximum or very high on $24^{\text {th }}$ followed by $22^{\text {nd }}$ after which it started to decrease towards the minimum value. This means that the geomagnetic activity is almost stable for the month of the year.

On the $15^{\text {th }}$ day of February, 2012, ionospheric dissipation was high, followed by average values during the $7^{\text {th }}, 19^{\text {th }}, 20^{\text {th }}$ and $26^{\text {th }}$ day of the month and least on the $17^{\text {th }}$, which means that the electric conductivity within the ionosphere begins to increase during these days.

From Figure3, we see that on $1^{\text {st }}$ day of the month, the dissipation is of the order of $10^{7} \mathrm{GJ}$ with the peak value on the $7^{\text {th }}, 15^{\text {th }}$ and average values on $12^{\text {th }}$ and $28^{\text {th }}$. Such orders of magnitude indicate the charged particles only drift to each other without collisions with neutral particles within the ionosphere (Ahn, et. al,1998) thereby having both high thermal and drift energy.

The highest value of energy in Figure 4 occurs on $24^{\text {th }}$ and $25^{\text {th }}$. The peak value of dissipation and their minimum values for both Figure 5 and 6 are in the range of $10^{7} \mathrm{GJ}$ and $10^{6} \mathrm{GJ}$ respectively.

The dissipation is very high compared to the other days of the year on the $9^{\text {th }}$, and $15^{\text {th }}$ of July, 2012 with energy $5.81 \times 10^{7} \mathrm{GJ}$ and $5.94 \times 10^{7} \mathrm{GJ}$ respectively. This trend shows that the solar wind current has imposed electric field in the ionosphere, thus dissipating huge amount of energy (Candrescu, et. al 1995).

On the $6^{\text {th }}$ and $16^{\text {th }}$ of August, 2012, the dissipation energy is almost the same. This is also true for the $19^{\text {th }}$ and $22^{\text {nd }}$ with least values on the $10^{\text {th }}$ and $31^{\text {st }}$. within the same month and also lonospheric dissipation is high on $2^{\text {nd }}$ followed by sudden increase on the $3^{\text {rd }}$ before it starts decreasing towards an average value on the $4^{\text {th }}, 7^{\text {th }}$ and $19^{\text {th }}$ of September,2012. For these months, the concentration of neutral particles within the ionosphere seems to dominate the charged particles.

The charged particles drift relative to each other and neutral particles such that only some part of the particles velocities will be converted to thermal energy for dissipation in the ionosphere (Kallio, et al, 2000).

Figure7 gives the summary of the results and it is clear from the figure that the estimated daily Ionospheric Dissipation Energy is $1.414393 \mathrm{E}+07 \pm 824154.1 \mathrm{GJ}$. This means that in a year this amount of energy is dissipated in the ionosphere daily, which is greater than the solar wind energy input estimated by Akasofu in 1981. His estimate was $1.7 x E 06 G J$. This clearly indicates that there are possibly other sources of energy dissipation in the ionosphere and not only the energy deposition by solar wind. The collisions between imposed electric field and neutral particles may possibly account for this energy increase. 


\section{CONCLUSION}

The estimated value for ionospheric energy dissipation was found to be $1.414393 \mathrm{E}+07 \pm 824154.1 \mathrm{GJ}$ which is greater than the estimated energy input by Akasofu in 1981. This clearly indicates that there are other

\section{REFERENCES}

Ahn, B.H., Robinson, R.M., Kamide, Y. and Akasofu, S.I. (1983). Electric Conductivities, Electric Fields and Auroral Particle Energy Injection Rate in the Auroral lonosphere and Their Empirical Relations to the Horizontal Magnetic Disturbance, Planet. Space Sci., 31,641

Ahn, B.H et al.,(1998). An ionospheric conductance model based on ground magnetic disturbance data, J.Geophys.Res. , 103, 14,769-14,780

Akasofu, S.I.,(1981).Energy Coupling Between the Solar Wind and Magnetosphere, Space Sci. Rev., 28, 121

Codrescu, M.V., Fuller-Rowell, T.J and Foster, J.C.(1995). On the importance of EField Variability for Joule Heating in the High Latitude Thermosphere, Geophys. Res.22,2393.

Davis, T.N. and Sugiura, M.(1966). Auroral Electrojet Index $\mathrm{AE}$ and Its Universal Time Variation, J. Geophys. Res. 71,785 .

Eija Tanskanen,(2002).Terresterial Substorms as a Part of a Global Energy Flow, Finnish Meteorological Institute Contributions No. 36 .

Kallio, E.I., Pulkkinen T.I., Koskinen H.E.J., Vilianen A., Slavin J.A. and Ogilvi K. (2000), Loading- Unloading Process in the Night side lonosphere, Geophys., Res., Lett, 27, 1627-1630.

Liou, K., Newell, P.T., Meng, C.I, Brittnacher, M., and Parks, G.,(1998). sources possibly the collisions between imposed electric field and neutral particles may account for this energy increase and not only the energy deposition in the ionosphere as the sun constantly release energy, which is carried via the solar wind into the interplanetary space.

Characteristics of the solar wind controlled auroral emissions, J. Geophys. Res., 103,17,543-17,557

Mayaud, P.N., (1980).Deviation, Meaning and Use of Geomagnetic Indices, AGU Geophysical Monographs, New perspectives on Earth's magneto tail, 22

Østgaard, N., Vondrak, R. R, Gjerloev, J.W. and Germany, G.,(2002) A Relation Between the Energy Deposition by Electron Precipitation and Geomagnetic Indices during Substorms, J. Geophys. Res. 107(A9), 1246, doi:10.1029/2001JA002003

Palmroth, M., Janhunen P., Pulkkinen T.I., Aksnes A., Lu G., Østgaard N., Watermann J., Reeves G.D. And Germany G.A (2005). Assessment of Ionospheric Joule Heating by GUMICS4MHD Simulation, AMIE and satellitebased Statistics: toward a synthesis Ann.Geophys.23, 20512068

Vanhamaki H., A. Yoshikawa, O. Amm and R.Fujii (2012) lonospheric Joule Heating and Pointing Flux in Quasi-static Approximation, J. Geophys. Res., 117, A0832,doi: 1029/2012JA017841

Wilson G. R., Weimer, D. R, Wise, J.O. and Marcos, F. A. (2006), Response of the Thermosphere To Joule Heating and Particle Precipitation, J. Geophys. Res., 111, A10314, doi: 10.1029/2005JA011274 